Viewpoint

\title{
Mental health and politics since the eurozone crisis: The role of mental health professionals
}

\section{A R T I C L E I N F O}

\section{Article history:}

Received 6 August 2019

Available online 8 September 2019

\section{Keywords:}

Economics and psychiatry

Emergency

Psychiatry in Europe

Social and cross-cultural psychiatry

Ethics and human rights

Health economics

\begin{abstract}
A B S T R A C T
Some of the most immediate health effects of the 2008 economic crisis concerned the mind, not the body Rates of generalized anxiety, chronic depression, and even suicide spiked in many European societies. This viewpoint highlights the role of mental health professionals in responding to this emergency, and argues that their sustained mobilization is necessary to its long-term resolution.
\end{abstract}

(c) 2019 Elsevier Masson SAS. All rights reserved.
Some of the most immediate health effects of the 2008 economic crisis concerned the mind, not the body. Rates of generalized anxiety, chronic depression, and even suicide spiked in many European societies. In a 2016 review of research concerning the downturn's effect on mental health, the European Psychiatric Association found a "broad consensus" that the unemployment, indebtedness, precarious working conditions, inequalities, social isolation, and housing instability produced by economic crisis had negatively affected mental health. [1] Responses to this public health emergency varied, often in ways predictably determined by other political and economic factors but one factor remained constant: the sustained mobilization of mental health workers in support of public mental health services.

\section{Mental health outcomes}

To be sure, the bulk of the incidence in mental health disorders comprises "common," not "serious," conditions. This clinical distinction is significant. Unlike people with serious mental illness (e.g., schizophrenia, bipolar disorder), people with common mental disorders (e.g., generalized anxiety, substance abuse) do not present psychotic symptoms, and as a result, they often require less intensive care. The most common mental health effects of the economic crisis are diminished psychological well-being, depression, anxiety, insomnia, alcohol abuse, and suicidal behavior. Pejorative references to the "worried well" often intimate the conclusion that this group diverts valuable mental health resources from those with more serious conditions (and often fewer financial means).

Yet common disorders also can lead to significant personal suffering, high service use, and when left unattended, devastating social consequences. ${ }^{1}$ Perhaps the most striking crisis-induced mental health development is the increase in suicides. In Greece, researchers found that austerity measures increased the total suicide rate by $35.7 \%$. The epidemic spread as others became aware of the uptick: after a cash-strapped pensioner commit suicide in front of the Greek parliament in April 2012, the national suicide rate temporarily increased by another $29.7 \%$. [2] Researchers have observed similar trends elsewhere, especially among males. One study estimated that the British recession led to about 1000 excess suicides in England, 846 of them male [3]; and another, crosscountry, study found that an one percentage point increase in unemployment would increase the number of male suicides in the EU-27 by approximately 500 each year [4].

Also worrisome are the changes in alcohol abuse and addictive behavior. In many countries, the unemployed, indebted, and evicted have turned to cheap drugs and binge drinking to pacify their distress. A post-crisis study of the illicit drug content in Italian wastewater found that, while the daily loads of expensive drugs (cocaine, heroin) had fallen since before the crisis, the daily loads of inexpensive drugs (methamphetamine, cannabis) had increased. [5] Similarly the number of alcohol-related disorders in Spain increased by $4.6 \%$ between $2006-2010$, which researchers traced to the combined risks of household unemployment and mortgage payment difficulties [6].

The prevalence of poor mental health in Italy, for example, increased by $4 \%$ between 2005 and 2013. The effects of the crisis are particularly pronounced among young males, unemployed

\footnotetext{
${ }^{1}$ Moreover, those with pre-existing serious conditions suffer doubly during economic crisis, experiencing both an uptick in milder symptoms and often losing access to treatment for their severe conditions (Ibid).
} 
persons, and low-income individuals, especially those in Southern Europe and other countries severely affected by the crisis. This is not to say that other countries have not observed related trends. The paucity of media attention on the incidence of alcoholism in Sweden, poor sleep in Finland, or psychotropic drug consumption in France should not lead one to assume immunity elsewhere. [1,7]

\section{Government and political responses}

European governments hence find themselves in a crisis of their own making. On the one hand, fiscal and economic authorities are responsible for the severe economic austerity that prompted and protracted the increase in poor mental health. On the other hand, health and welfare authorities are responsible for redressing it, often with limited means. Governments have addressed this dilemma in different ways. Several factors condition their responses.

Among the most important determinants of national responses to the mental health crisis are, in fact, supranational factors: the economic impositions of European Commission, the European Central Bank and the International Monetary Fund (often referred to as the "troika") constrain the abilities of both national economic authorities and national welfare authorities to address the crisis. For example in Greece, which imposed some of the most severe austerity measures in Europe, annual state spending on mental health was halved in 2012, and it has been cut further in each subsequent year. [8] By contrast, countries facing fewer troika restraints have more control over the policy levers that could improve mental health.

Yet merely controlling national policy levers cannot predict a country's ability to rebound from the crisis, nor its willingness to boost the mental health infrastructure. Historical policy trends and institutional arrangements determine the baseline conditions for reform. For example in Spain, the robust National Health Service took measures to treat the increase of mental health conditions at the primary care level. [6] In the Spanish case, both the avoidance of a Greek-style comprehensive bailout and the institutional capacity of its health service contributed to this response.

The ultimate decision to reform-and how - rests on politicians and policy-makers. It is difficult to gauge the effect of the populist turn on the European mental health crisis, but at the very minimum, its rhetorical emphasis on social solidarity (often at the exclusion of non-nationals) suggests a political willingness to expand employment, increase social benefit transfers, and develop health resources. For example, the populist coalition that currently governs Italy has enacted a basic income scheme. [9] Although highly controversial, the policy aligns expert recommendations to reduce social and income inequality in the interest of improving mental health [1]. Some observers might interpret these recommendations as supportive of the League-Five Star policy.

\section{The common denominator}

Despite these differences, nearly every European country facing an uptick in poor mental health has encountered a similar concomitant trend: resistance to austerity from mental health professionals. Cuts to mental health services have mobilized the psychiatric workforce. As suicides and depression increased in Greece, for example, the patient populations of psychiatric hospitals doubled their maximum capacity. In response, hospital unions denounced both the cuts to public psychiatric hospitals and the cuts to public sector pension. The Health Ministry now runs a pilot program to ensure round-the-clock access to psychiatric care, and is opening 19 new mental health clinics. $[8,10]$ Similar developments have occurred across
Europe, where union leaders representing public mental health workers have led protests, garnered media attention, and pressured policy-makers to increase payments to mental health services.

This common denominator - the mobilization of public mental health workers - underscores the critical role of professionals in sustaining and expanding psychiatric care. People with chronic and severe mental illnesses often lack the ability to demand services from government. Absent that demand, the scope and generosity of psychiatric services often depend on the advocacy of those employed by them - that is, of psychiatrists, psychiatric nurses, clinical psychologists, social workers, and administrators. Mental health professionals must continue to support these services, both during and after times of economic duress - for despite the passage of time, the legacy of the European economic crises remains a public mental health concern.

\section{Acknowledgements}

For their comments on earlier drafts of this viewpoint, the author acknowledges Dominic Sisti, as well as Margitta Mätzke and the participants of the 2019 Council for European Studies conference roundtable on public health since the crisis.

\section{References}

[1] Martin-Carrasco M, et al. EPA guidance on mental health and economic crises in Europe. Eur Arch Psychiatry Clin Neurosci 2016;266(March (2))89-124, doi: http://dx.doi.org/10.1007/s00406-016-0681-x p 1; see also David Stuckler and Sanjay Basu, The Body Economic: Why Austerity Kills: Recessions, Budget Battles, and the Politics of Life and Death (New York: Basic Books, 2013).

[2] Branas CC, et al. The impact of economic austerity and prosperity events on suicide in Greece: a 30-Year interrupted time-series analysis. BMJ Open 2015;5 (February (1)), doi:http://dx.doi.org/10.1136/bmjopen-2014-005619 e005619e005619.

[3] Barr B, et al. Suicides associated with the 2008-10 economic recession in England: time trend analysis. BMJ 2012;345(August (14)), doi:http://dx.doi. org/10.1136/bmj.e5142 2: e5142-e5142.

[4] Breuer Christian. Unemployment and suicide mortality: evidence from regional panel data in Europe: unemployment and suicide mortality in European regions. Health Econ 2015;24(August (8)):936-50, doi:http://dx.doi. $\operatorname{org} / 10.1002 /$ hec.3073.

[5] Zuccato Ettore, et al. Changes in illicit drug consumption patterns in 2009 detected by wastewater analysis. Drug Alcohol Depend 2011;118(November (2-3)):464-9, doi:http://dx.doi.org/10.1016/j.drugalcdep.2011.05.007.

[6] Gili Margalida, et al. The mental health risks of economic crisis in Spain: evidence from primary care centres, 2006 and 2010. Eur J Public Health 2013;23(February (1)):103-8, doi:http://dx.doi.org/10.1093/eurpub/cks035.

[7] Clainche Christine Le, Lengagne Pascale. The effects of mass layoffs on mental health. Working Paper Paris: Institut de recherche et documentation en économie de la santé; 2019. . May https://www.irdes.fr/english/workingpapers/078-the-effects-of-mass-layoffs-on-mental-health.pdf.

[8] Kitsantonis Niki. Greece, 10 years into economic crisis, counts the cost to mental health. New York Times; 2019. . February 3 https://www.nytimes.com/ 2019/02/03/world/europe/greece-economy-mental-health.html.

[9] Giuffrida Angela. Italy rolls out 'citizens' income' for the poor amid criticisms. The Guardian; 2018. . March 6 https://www.theguardian.com/world/2019/ mar/06/italy-rolls-out-citizens-income-for-the-poor-amid-criticisms.

[10] Staff TNH. The toll Greece's crisis took on mental health care. February 17 . The National Herald; 2019. https://www.thenationalherald.com/231027/the-tollgreeces-crisis-took-on-mental-health-care/.

Isabel M. Perera

University of Pennsyvlania, Blockley Hall, 14th Floor, 19104, Philadelphia, PA, United StatesE-mail address: iperera@upenn.edu

(I. Perera).

Received 6 August 2019

Available online 8 September 2019 